\title{
Sexual behaviour unsurveyed
}

The British government's refusal to countenance a survey of people's sexual behaviour is demoralizing for those concerned but should not deter them from pushing ahead with the project.

WE are all familiar with the idea that people who work on distasteful projects, say the optimum design of dum-dum bullets fired at mammalian torsoes, will cast a pall on the most cheerful company if they talk too openly about their work. But not AIDS researchers, surely? Those I remember most vividly are a group of physicians at the San Francisco City Hospital some years ago; mostly in their early thirties, there could have been no reason, except heroism and the hope that their experience might help the treatment of patients still to fall ill, why they should thanklessly have been running a hospital ward for the indigent and terminally sick. Yet they were a brisk and cheerful lot, and their humour was infectious. No doubt it helps if what you are doing commands most people's approval.

Those in Britain who have been designing the temporarily abortive "National Survey of Sexual Attitudes and Lifestyles" are a different case. Those who have been talking on the telephone are fully aware that little has been done in this field since Kinsey in the early 1950 s (and even that, they say, was more like a collection of case-studies with numbers than a survey, given the biassed character of the sample). But one whom I have never met except by telephone put the personal predicament strikingly one day last week: "She's made us feel ... well you know, ... naughty." "She", of course, is the prime minister, Mrs Margaret Thatcher, who declined to let British government agencies spend money on the project. The peculiarly English word "naughty" is to be understood, on this occasion, as "prurient".

All research requires that a person should invest his or her reputation in that of what emerges, but there are some fields of research in which people are especially vulnerable to external insult. It seems doubly cruel that the same people have to suffer self-inflicted insults, otherwise what the Freudians would call guilt, born of nothing more substantial than one person's disapproval.

Luckily, other researchers seem to have been mostly encouraging. But I did meet one sociologist last week who volunteered that he'd have been exceedingly cautious of a proposal to measure sexual attitudes and lifestyles (or behaviour?), given the pitfalls that abound in trusting what people will tell even professional pollsters. But in the trade, it seems to be acknowledged that the questions that most vigorously rouse resentment are about personal incomes, not behaviour. Physicians seem particularly supportive of the project; even on such a scale as that proposed - there would have been 20,000 respondents in the full-scale survey - the data may not pin down the parameters that epidemiologists need to calculate the likely spread of AIDS, but might they not say something about pappiloma virus and cervical cancer?

The potential benefits of a substantial survey along these lines would be even more direct. From the data gathered in the the pilot surveys in 1987 and 1988 (some of which were presented at a meeting of the Society of Social Medicine at Manchester last week), it seems clear that there is a great deal to be learned about the sexual behaviour of adolescents that would quickly inform social programmes now designed in ignorance to cater for them.

That the median age of women at first heterosexual intercourse has fallen from more than 20 to 16 in two decades is, for example, unsurprising, given anecdotal evidence. But it is surprising that, even among the youngest age-group (16-24), nearly a quarter of first intercourses are innocent of contraception. In contrast with the older groups, condoms appear on more than half of these occasions, which might be good news for a government such as the British which has spent a great deal on advertising their utility in the prophylaxis of AIDS on television in the past few years. If the numbers responding had been greater, the chance of disentangling the several possible causes of what seems to have been a dramatic shift of practice would naturally have been much greater.

At this stage, when the numbers are small, it is understandable that there should be relatively little that bears directly on the epidemiology of AIDS. The most telling information would eventually have come from a sensitive knowledge of the rate at which people acquire new sexual partners; multiplied by the chance that an infected person will infect another, this quantity measures the chance that people will become infected. The figures so far show that the average number of heterosexual partners of men in the course of a lifetime is 11.0 and of women 2.9. But the rate of spread of sexually transmitted AIDS depends not on the average but on the behaviour of the most sexually active people, which argues again for the weight of numbers.

The need for larger numbers is further emphasized by the need that a survey intended to throw light on the spread of AIDS should include sufficiently large numbers of those in the high-risk groups, homosexual and bisexual men, for example. Only then can a survey of this kind be related to other kinds of studies, perhaps the tracing of infected people's partners. One of the disconcerting features of the British pilot survey is that the proportion of men reporting homosexual partners is too small to be believable; the succeeding feasibility survey, involving the greater use of self-completed questionnaires, seems to have been more successful.

That appears also to have been true of the response rate, the commonly-used indicator of the representativeness of any survey. In the original pilot survey, the response rate was less than a half, but in last year's feasibility study, it had increased to 62 per cent of those still to be found at their random addresses. But 24 per cent refused point-blank to cooperate, which is too great a proportion for comfort. In passing, it would be interesting to see whether responses to a survey carried out in the next few weeks (there is no time, of course) would have been increased or decreased by the government's refusal to allow this study to be sanctioned, but that is another matter.

Meanwhile, there is a broad question affecting the whole scientific community. The British government is within its rights to say no to whatever it likes, and nobody can justly complain that it has interfered with academics' freedom. On one view, the refusal merely reflects the government's calculation of how many voters dislike the whole idea, and who probably predominate among those who decline to be interviewed. The moral is that the disappointed researchers, but especially their colleagues, should carry the argument for greater awareness to the public.

In the long run, that is how communities such as the British will come to recognise that statistical measures of their behaviour is not an invasion of their privacy, but can be a great social benefit. But there is also a short-term benefit to be won. It is natural that people who have worked for two years on a project suddenly halted should be disconsolate, but the government is not the only possible source of funds. This team deserves a fund-raising drive.

John Maddox 